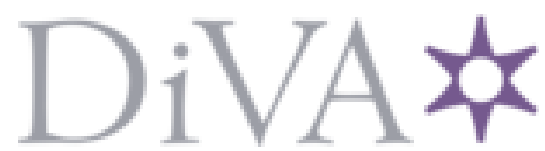

http://www.diva-portal.org

\title{
Postprint
}

This is the accepted version of a paper presented at IEEE International Energy Conference (ENERGYCON).

Citation for the original published paper:

Herre, L., Wouters, P., Steennis, F., de Graaff, R. (2016)

On the electromagnetic coupling of AC and DC circuits on hybrid transmission towers.

In: IEEE International Energy Conference (ENERGYCON) (pp. 1-6). Leuven: IEEE

http://dx.doi.org/10.1109/ENERGYCON.2016.7514143

N.B. When citing this work, cite the original published paper.

(C) 2016 IEEE. Personal use of this material is permitted. Permission from IEEE must be obtained for all other uses, in any current or future media, including reprinting/republishing this material for advertising or promotional purposes, creating new collective works, for resale or redistribution to servers or lists, or reuse of any copyrighted component of this work in other works.

Permanent link to this version:

http://urn.kb.se/resolve?urn=urn:nbn:se:kth:diva-191152 


\section{On the Electromagnetic Coupling of AC and DC Circuits on Hybrid Transmission Towers}

\author{
Lars Herre \\ Peter Wouters, Fred Steennis \\ Department of Electrical Engineering \\ Eindhoven University of Technology \\ Eindhoven, the Netherlands \\ lherre@kth.se
}

\author{
Roald de Graaff \\ Energy Advisory \\ DNV GL \\ Arnhem, the Netherlands \\ roald.degraaff@dnvgl.com
}

\begin{abstract}
Transmission system limits, originating from rightof-way permission processes for new corridors, can be surpassed by erecting new circuits in close proximity, or even on common structures. Especially for long distance bulk power transfer, high voltage direct current technology promises superior features. Adding a circuit to a transmission corridor is one method of significantly increasing power transfer capability. Converting an existing AC circuit for DC operation is another method that additionally decreases investment in new lines and towers. Consequences of such application are various AC/DC interaction phenomena on either AC or DC lines for both steady and transient conditions. This paper presents a study on AC/DC transmission system interactions for a hybrid tower configuration. In normal operation DC voltage showed no significant fundamental AC frequency component, while induced transient overvoltages displayed notable levels.
\end{abstract}

Index Terms-HVDC transmission, hybrid power systems, power system analysis computing, PSCAD/EMTDC.

\section{INTRODUCTION}

Two basic alternatives exist when erecting new onshore transmission corridors: underground cables or overhead lines. With transmission right-of-way at a premium, there are increased incentives to construct new DC lines in close proximity to existing corridors, or even on common structures. Therefore an alternative to opening new corridors suggests converting AC lines on existing towers for DC operation. High voltage direct current (HVDC) power electronic devices offer a promising solution to increase bulk power transfer and enhance flexible system operation.

Hybrid towers accommodating both AC and DC lines include the concern of induced voltages and currents due to capacitive and inductive effects of the two circuits by elements illustrated in Fig. 1. This electromagnetic coupling comprises both steady state and transient conditions. In steady state a fundamental frequency component is superimposed on the DC voltage, and a DC voltage component is induced in disconnected AC lines. In transient conditions such as faults and line energization the induced overvoltages and currents in both systems can be several times higher.

The concept of converting an AC circuit to DC was first described in [1] for Current-Source Converters (CSC). Reference [2] presents a study of induced overvoltages and

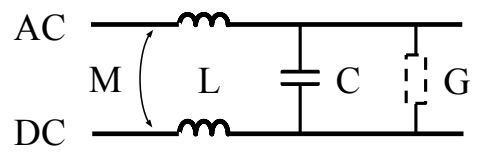

Fig. 1. Coupling elements of parallel AC and DC lines

introduces blocking filters as mitigation measure. Interaction phenomena of a 12 pulse bridge studied in [3] are found to be not negligible, yet uncritical. For CSC the major concern resulting from fundamental frequency component in the DC circuit is possible core saturation in the converter transformers due to DC offset. The authors of [4], [5], [6] demonstrated that the induced fundamental current would be seen as a DC current and $2^{\text {nd }}$ harmonic current on the line side of the CSC transformer. The DC current component could cause an offset in the transformer flux which saturates the core in one direction. This saturation in turn would inject a series of even harmonics in both the $\mathrm{AC}$ and $\mathrm{DC}$ sides that can affect overall system performance. The authors of [7] lay out a comprehensive summary of interaction and propose mitigation in form of

1) $\mathrm{AC}$ line transposition

2) blocking filters for the fundamental $\mathrm{AC}$ component

3) suitable DC converter control.

In [8] a study on the Ultranet project in Germany is presented which envisions converting one existing AC circuit for bipolar VSC operation. The authors propose mitigation by means of blocking filters or suitable converter control. Possible hybrid tower configurations for the aforementioned project are shown in [9] and based on [10], [11]. In [9] a mathematical calculation of the induced fundamental AC component in open circuited DC lines of Ultranet is presented.

\section{HVDC TRANSMISSION}

HVDC transmission comprises features that prove advantageous when bulk power transfer is considered. Conductor size can be smaller for the same rated power which implies that more power per tower can be achieved. Application areas where HVDC is favourable are long distances, coupling of 
asynchronous AC grids, connection of remote or offshore generation, active and reactive power flow control. New technologies are emerging and ambitious projects already envision an interconnected DC Supergrid.

Traditionally, VSC converters have been divided by topology with respect to the number of switchable voltage levels. VSC converters may also be classified in those using switch type valves and those using controllable voltage source type valves [12] as in Fig. 2.

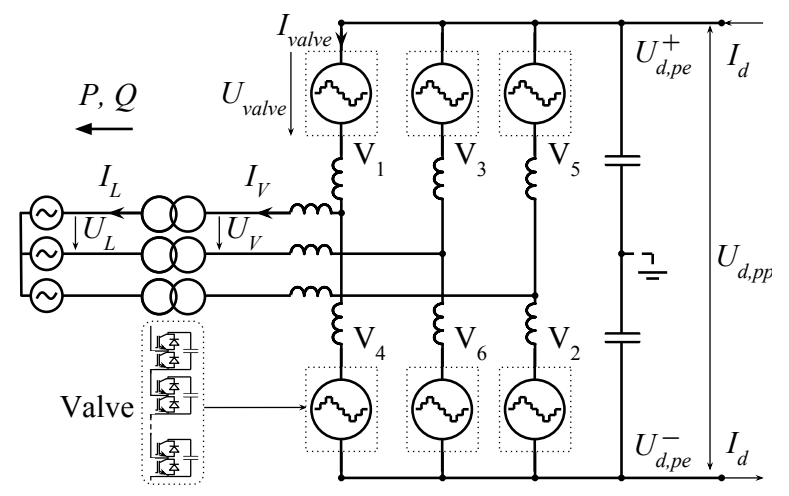

Fig. 2. Converter using controllable voltage source type valves such as MMC

\section{MMC MODELLING}

\section{A. Model Review}

The Modular Multilevel Converter (MMC) introduced in [13] constitutes an important advance in HVDC converter development. Various types of computational MMC models have been proposed for particular requirements i.e. accuracy and simulation speed [14]. A fast model suitable for electromagnetic transient (EMT) studies was introduced in [15]. A PSCAD implementation from Manitoba HVDC described in [16] was validated in [17]. Further simplifications have been suggested in [18] and improved representations of the blocking state were introduced in [19], [20] and [21]. In [20] the impact of the level of detail in MMC modeling on the simulation results is investigated.

A comprehensive summary of different types of computational models of MMC for simulation is found in [14] and is symbolized in Fig. 3. EMT simulation (using $T_{1-4}$ models)

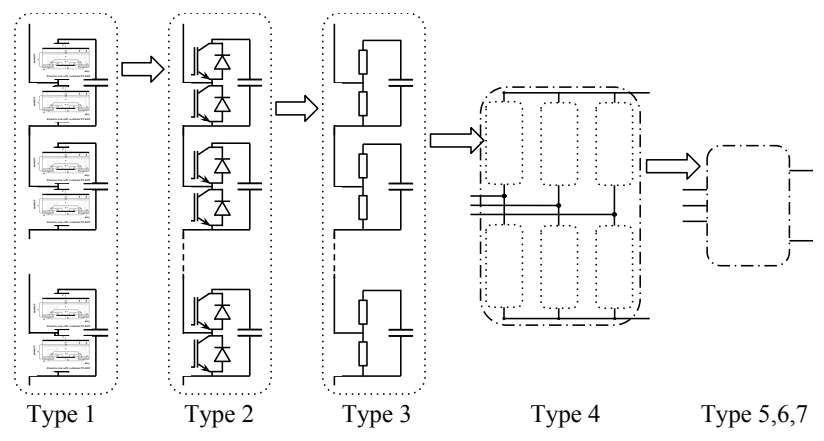

Fig. 3. Types of Simulation Models for MMC is highly detailed but time consuming, while quasi-stationary phasor simulation (using $T_{6,7}$ models) is computationally efficient but less accurate.

\section{B. Type 4: Detailed Equivalent Model}

The $\mathrm{T}_{4}$ Detailed Equivalent Model (DEM) represents the fastest type which is still applicable for EMT studies and thus was implemented in this work. The method of simplifying the submodules (SM) in each arm to one single valve representation is described here in brief. For a more detailed description the interested reader is referred to [14] - [20].

The general idea is to represent all SMs of one converter arm in one valve, thus decreasing the number of electrical nodes while maintaining calculation accuracy. Based on the Type 3 model, IGBT and diodes are discretised by two-state resistive devices. Fig. 4 illustrates the topology, model discretisation and Thevenin equivalent representation of one SM.

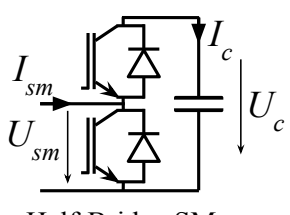

Half-Bridge SM

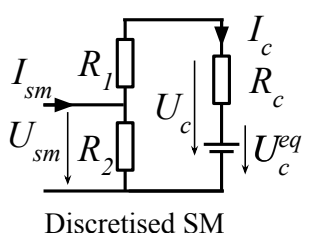

Discretised SM

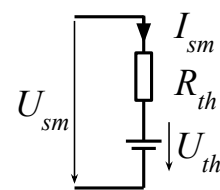

Thevenin eq.
Fig. 4. Half-Bridge Submodule, model simplification and Thevenin equivalent

Finally the valve equivalent parameters are expressed as the sum of Thevenin equivalent parameters of all SMs in one converter valve. In the DEM the entire arm is represented only by the valve reactor, valve equivalent voltage source $U_{\text {valve }}$ and resistance $R_{\text {valve }}$.

\section{Blocking State Representation}

The above model reduction however also contains a major inaccuracy in the blocked state, where numerical oscillations have been reported [19], [20]. These issues are related to the equivalent circuit being only based on gate signals and $\operatorname{sign}\left(I_{\text {valve }}\right)$, not considering the voltages across diodes. These oscillations are reflected in the valve equivalent voltage and can lead to instability in operating modes as start up or fault.

To the authors' knowledge three methods to cope with this issue were proposed in literature. Fig. 5 illustrates the different methods. Model (a) [19] proposes to store an additional array of $U_{t h, i}$ for checking the state of the bypass diode based on the previously stored voltage $U_{t h, i}(t-\Delta t)$. The model (b) described in [21] uses a bypass diode that conducts in the blocking state, and the implementation of Manitoba HVDC (c) uses an IGBT that is fired in the blocking state to bypass the valve. The bypass element must then have a resistance equivalent to the sum of all bypass diodes in the valve.

During normal operation, $B_{n} / S_{n}$ is conducting. In the blocking state they open and $D_{b} / S_{b}$ enable the valve current to bypass the valve equivalent. In positive direction, $I_{\text {valve }}$ always passes the valve equivalent. The first proposal (a) requires more storage and for high accuracy an iterative 


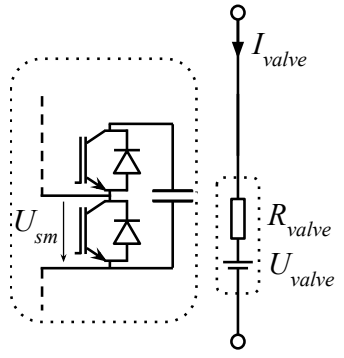

(a) Store $\left[U_{s m}\right]_{1 \times \mathrm{i}}$

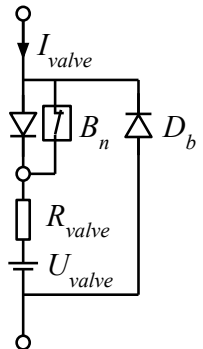

(b) Bypass Diode

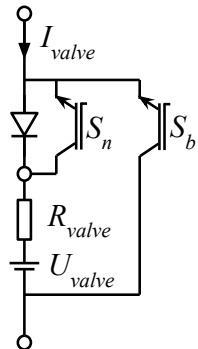

(c) Bypass IGBT
Fig. 5. Methods of coping with the blocked state

process is recommended. Therefore (b) and (c) prevail in speed and accuracy. Method (c) was implemented since it incorporates the additional turn-off capability of the bypass path.

\section{Control System}

Lower level controls receive reference voltage $U_{\text {ref }}$ and angle $\theta$ from upper level controls. Output are gate signals for the switches to insert or bypass capacitors of specific SMs.

1) Circulating Current Suppression Control (CCSC): As suggested in [14] a PI controller in dq frame with a negative sequence and synchronized with the $2^{\text {nd }}$ harmonic was employed to suppress circulating currents.

2) Modulation: Common AC voltage modulation techniques include mostly variations of PWM and become less efficient as the number of SMs increases. Upon comparison, [14] finds that Nearest Level Control (NLC) results in lowest THD. In this study NLC using voltage magnitude was adapted. First, the CCSC term is added to the reference of top and bottom valves of phases $a, b, c$. The number of SMs ordered in the on state, $N_{o n}$ is then determined by comparing the arm reference $U_{\text {ref }}$ to the number of switchable levels, i.e by selecting the nearest integer $N_{\text {on }}(t)=N I N T\left(\frac{N}{2} \cdot\left[U_{\text {ref }}(t)+1\right]\right)$.

3) Capacitor Balancing Algorithm (CBA): During normal operation switching a half-bridge SM results in four possible states depending also on the direction of current $I_{s m}$. The purpose of CBA is to maintain capacitor voltages balanced by selecting appropriate SMs to be switched depending on their state of charge, i.e. capacitor voltage $U_{c}$.

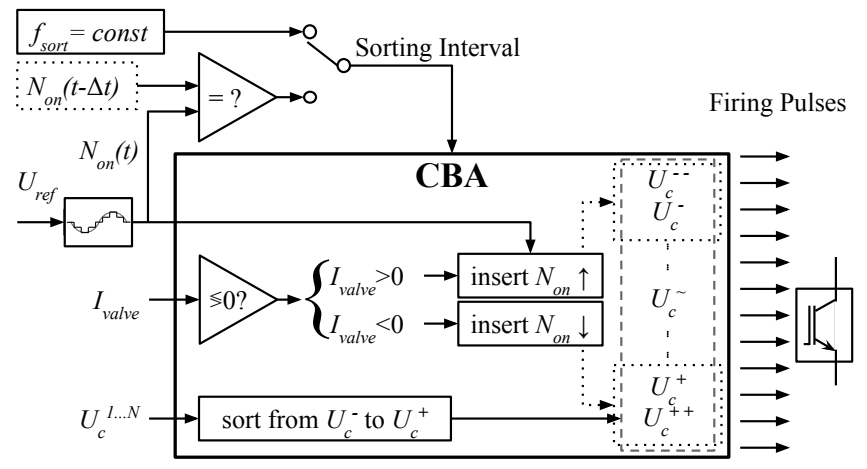

Fig. 6. Proposed Capacitor Balancing Algorithm
Since CBA requires only the number of SMs ordered in the on state and direction of current it can be easily adopted in the control strategy. Fig. 6 illustrates the proposed implementation.

\section{Electromagnetic Coupling}

The electric field of an $\mathrm{AC}$ transmission line induces voltages on nearby objects by the capacitive voltage divider between line, object and ground. Evaluation of electric field effects of AC lines involves human perception, annoyance, and safety with respect to voltages and currents induced on these nearby objects. The electric field of a DC transmission line is static and therefore only able to induce a voltage in disconnected parallel lines.

The magnetic field of an $\mathrm{AC}$ transmission line induces voltages on nearby objects by inductive coupling between the line and nearby parallel objects. In addition to above concern, inductive effects include interference to railroad signals, noise in telephone circuits, and impairment of pipeline protection systems. Under normal operating conditions with constant power flow, the magnetic field of a DC transmission line is static, and therefore unable to induce voltages on nearby bodies and not considered further in this paper.

\section{A. Coupling Elements}

Electromagnetic coupling of overhead lines can be computed based on distributed parameters of system $\mathbf{Y}$ and $\mathbf{Z}$ matrices, comprehensively explained in [22]. Shunt Admittance Matrix $\boldsymbol{Y}$ consists of complex elements whose real value represents leakage losses from corona and leakage currents along conductor surface and whose imaginary part account for conductor-to-ground and conductor-to-conductor capacitive coupling. Series-Impedance Matrix $\boldsymbol{Z}$ consists of a self impedance $\mathbf{Z}_{s}$ and a mutual impedance $\mathbf{Z}_{m}$ that accounts for mutual coupling via ground, where self impedance encompasses conductor and earth return path.

\section{B. Implementation in PSCAD}

Mutual coupling is a standard feature of PSCAD that depends on tower geometry, conductor and earth properties. Mutual impedance between aerial conductors in PSCAD is obtained as the Deri-Semlyen approximation of Carsons Integral. Frequency dependent phase domain method was selected for this study, whose detailed implementation in EMTDC is described in [23]. Fig. 7 shows the physical configuration of $\mathrm{AC}$ and $\mathrm{DC}$ transmission lines that was implemented in the simulation and corresponds to the D-Tower topology of Ultranet, where the neutral conductor $D C n$ was only used in bipolar configuration with metallic return.

\section{Simulation Environment}

A 2-Terminal test system with monopolar and bipolar converters was developed in PSCAD based on aforementioned DEM and controls as depicted in Fig. 8. Upper level converter topology and controls were adopted from [14]. The parallel $\mathrm{AC}$ and DC lines can be mutually coupled $\left(M_{1}\right)$ or not $\left(M_{0}\right)$ and coupled to the same $\left(B_{1}\right)$ or different AC buses $\left(B_{0}\right)$. The 


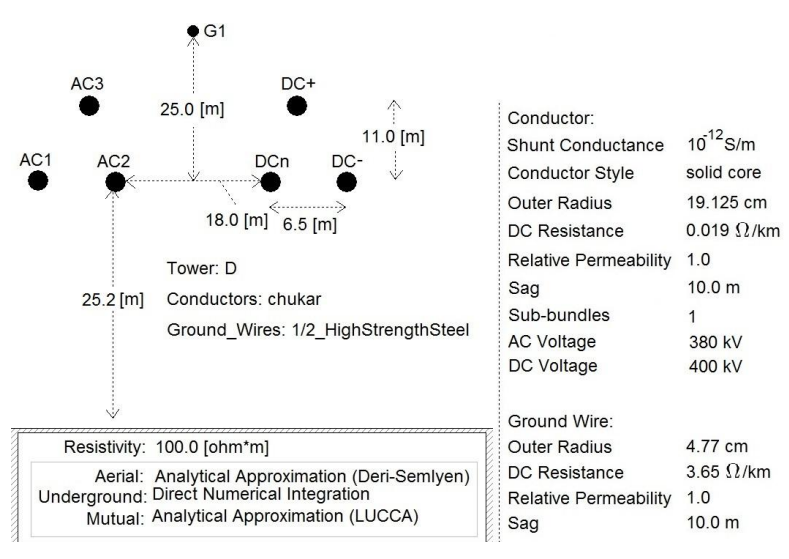

Fig. 7. The geometry of parallel AC and DC lines on a D-Tower

AC circuit can be untransposed $\left(T_{0}\right)$ or fully transposed $\left(T_{1}\right)$ over its length of $l=300 \mathrm{~km}$, i.e. 1 rotation in equidistant segments. Above parameters result in 8 different test system configurations for monopolar and bipolar converters.

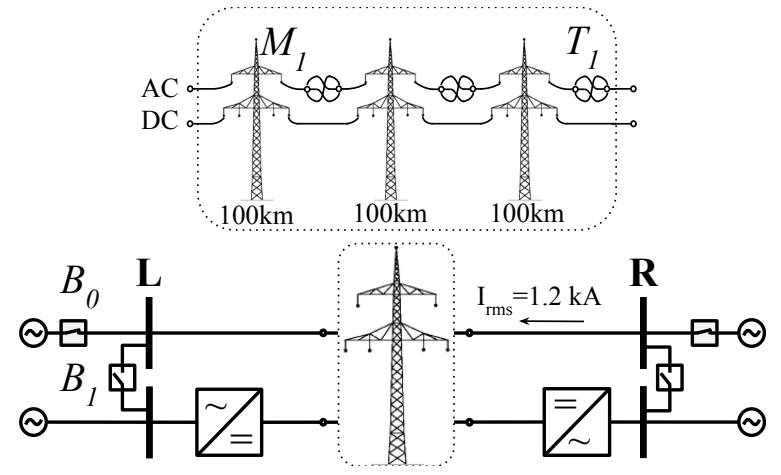

Fig. 8. Upper level view on the test system and hybrid transmission towers

The two AC sources have a short-circuit power rating of 30 GVA and represent strong AC networks, where angles are designed for a nominal current of $1.2 \mathrm{kA}_{\mathrm{rms}}$ to bus $\mathrm{L}$. The converter at bus $\mathrm{R}$ is in rectifier operation and is set to control the power transfer to bus $\mathrm{L}$ and $\mathrm{AC}$ bus voltage $U_{a c}^{R}$, the converter at bus $\mathrm{L}$ controls direct voltage $U_{d c}^{L}$ and $U_{a c}^{L}$.

Each converter unit accommodates pre-insertion resistors, $\Delta$-Y-transformer, star-point reactor and NLC phase units. The phase unit is comprised of two valves with CCSC, NLC modulation and CBA control with sorting at each simulation step.

\section{Simulation Results}

For evaluating the impact of mutual coupling three system points are of interest; the $\mathrm{AC}$ line side, $\mathrm{AC}$ valve side and the DC line side. In steady state voltage unbalance (VU) and total harmonic distortion (THD) are examined and compared to limits specified in standards (Dutch Grid Code). In addition to start-up and steady-state operation, several fault conditions are analysed. A fault duration of $150 \mathrm{~ms}$, clearing time of $50 \mathrm{~ms}$ for the AC circuit breakers and automatic re-closure after 300 ms were assumed. In transient conditions, the peak overvoltage due to induced power frequency voltages are documented.

\section{A. Model Validation}

In order to validate the developed model $\left(\mathrm{T}_{4}\right)$, a sequence of start-up, steady state, and single-phase-to-ground fault at $1.8 \mathrm{~s}$ is depicted in Fig. 9 for direct current and power. The Reference case describes two completely decoupled systems $\left(\mathrm{T}_{0} \mathrm{~B}_{0} \mathrm{M}_{0}\right)$ with the MMC implementation of Manitoba HVDC $\left(\mathrm{MH}_{\mathrm{M}_{0}}\right)$. The two other cases show the behaviour when lines are mutually coupled with the $\mathrm{MH}$ implementation $\left(\mathrm{MH}_{\mathrm{M}_{1}}\right)$ and the model developed in this work $\left(\mathrm{T}_{\mathrm{M}_{1}}\right)$ respectively. It can be seen that $\mathrm{T}_{4}$ yields comparable behaviour to $\mathrm{MH}$, both during steady and transient conditions and is thus suitable for conducting EMT simulation studies.
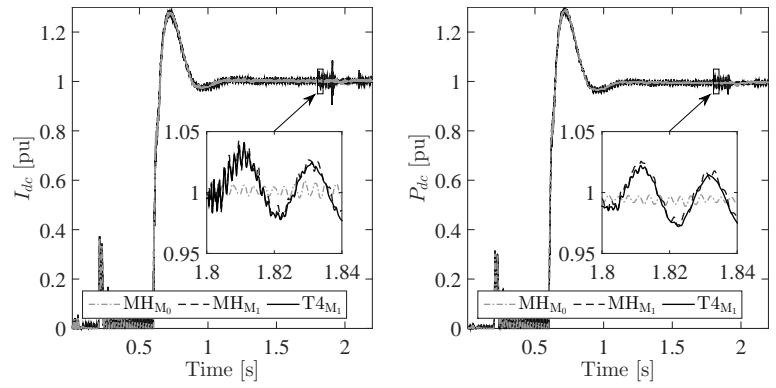

Fig. 9. Model comparison of direct current and power in monopolar system

Capacitor voltages of both models are displayed in Fig. 10 . It can be seen that the proposed algorithm sorts capacitors such that they maintain balanced operation with high resolution.
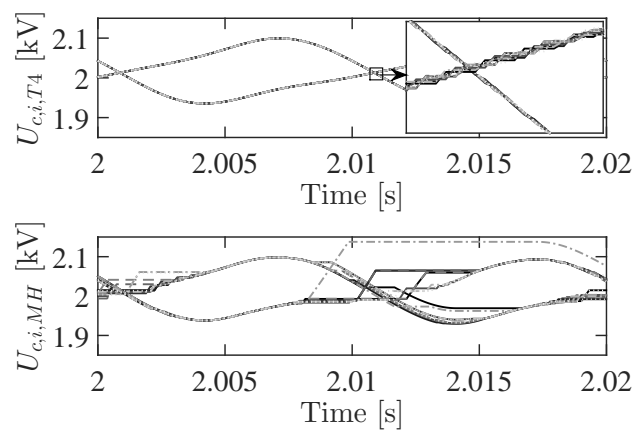

Fig. 10. Model comparison ( $\mathrm{T}_{4}$ top, $\mathrm{MH}$ bottom) of 10 randomly selected capacitor voltages in the upper and lower valve of one phase

\section{B. Steady State}

In the untransposed configuration pole-to-earth voltages with amplitude of up to $U_{d, p e}=5.8 \mathrm{kV}$ are induced. Due to the similar phase of induced pole-to-earth voltages the pole-topole voltage is of lower magnitude $U_{d, p p}=3.7 \mathrm{kV}$. When the $\mathrm{AC}$ circuit is transposed the induced voltage can be reduced by typically one order of magnitude. 
1) DC side: In steady state, the effect of mutual coupling on the direct voltage is examined. Analysis of the frequency spectrum revealed that the $50 \mathrm{~Hz}$ component can be well distinguished at the inverter during startup (not shown), then decreases to a level of $38 \mathrm{~V}$ (Monopole), i.e. $105 \mathrm{~V}$ (Bipole) when the SMs leave the blocking state and DC voltage control is activated.

Since the control is set to keep $U_{d, p p}$ constant, $U_{d, p e}$ needs special attention. The $50 \mathrm{~Hz}$ component on $U_{d, p e}$ reaches values of up to $2.2 \mathrm{kV}$ which is below the value of open ended DC lines. An analysis of the control signals in Fig. 11 showed a $50 \mathrm{~Hz}$ component of the d-axis current below $1 \cdot 10^{-3} \mathrm{pu}$ at both converters. Only in the direct current and

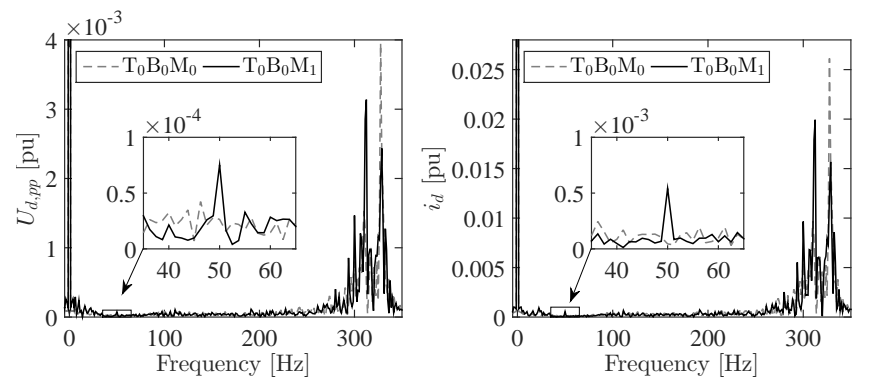

Fig. 11. Frequency spectrum of direct voltage and d-axis current

thus power, a notable $50 \mathrm{~Hz}$ component of around $0.01 \mathrm{pu}$ is calculated in normal operation. The DC voltage displays frequency components around $300 \mathrm{~Hz}$ ( $6^{\text {th }}$ harmonic) of up to $4 \cdot 10^{-3} \mathrm{pu}$.

2) $A C$ side: On the $\mathrm{AC}$ side both voltage unbalance (VU) and total harmonic distortion THD are examined. VU is expressed by the ratio of the negative $\left(U^{-}\right)$and zero $\left(U^{0}\right)$ sequence components to the positive $\left(U^{+}\right)$sequence as:

$$
k_{u}^{-}=\frac{U^{-}}{U^{+}}, \quad k_{u}^{0}=\frac{U^{0}}{U^{+}}
$$

THD defines the spectrum of harmonic voltages globally as

$$
T H D=\sqrt{\sum_{h=2}^{40} U_{h}^{2}}
$$

where $\mathrm{h}$ is the order of the harmonic. To asses the results, the limits in the Dutch Grid Code were used, which specifies that the 10 min mean rms values of $99.9 \%$ of $k_{u}^{-}$must not exceed $1 \%$ and $95 \%$ of THD must not exceed $5 \%$ during any period of one week.

In order to decrease the AC current through the valves a $3^{\text {rd }}$ harmonic voltage component of $0.15 \mathrm{pu}$ is generated by the converter which is not transferred to the transformer line side due to the valve side $\Delta$-windings. Analysis of harmonic content on the line side yielded typical harmonics $(2 n \pm 1) f$ where mutual coupling was found to have no significant impact. All tested configurations result in THD below $1 \%$. The magnitudes of these harmonics showed no significant difference for the examined cases.
In steady state operation the highest imbalance ratio imposed on the AC system was found to be $k_{u}^{-}=0.01 \%$ (Monopole) and $k_{u}^{-}=0.02 \%$ (Bipole) when AC and DC systems are connected and mutually coupled. The voltage imbalance ratios of monopolar and bipolar test systems are below $0.1 \%$ on the AC line sides. In all analysed cases the voltage unbalance remains below the limits defined in the Dutch Grid Code. It can be seen that line transposition can decrease the impact of mutual coupling on voltage unbalance on the line side.

\section{Transient Conditions on DC Side}

Several types and locations of faults must be distinguished. For the situation that there is only mutual coupling an unbalanced fault, such as a single-phase-to-ground fault would cause the highest impact on the DC system. When connected to the same AC system, severe AC faults such as three-phase faults would have higher impact. For this reason the impact of various AC faults is examined. Faults on different locations of the parallel AC system are applied at distances depicted in Table I.

TABLE I

LOCATIONS OF FAULTS ON THE PARALLEL AC SYSTEM

\begin{tabular}{ll}
$L_{i}$ & Location / distance to bus $\mathrm{L}$ \\
\hline$L_{1}$ & AC system at bus $\mathrm{L}$ \\
$L_{2}$ & AC line at bus $\mathrm{L}$ \\
$L_{3}$ & AC line at $1 / 3 \cdot l$ from bus $\mathrm{L}$ \\
$L_{4}$ & AC line at $1 / 2 \cdot l$ from bus $\mathrm{L}$ \\
$L_{5}$ & AC line at $2 / 3 \cdot l$ from bus $\mathrm{L}$ \\
$L_{6}$ & AC line at bus $\mathrm{R}$ \\
$L_{7}$ & AC system at bus $\mathrm{R}$ \\
\hline
\end{tabular}

The main concern of transient overvoltages are insulation levels, for which no standards exist at the time of writing for HVDC. The peak values of induced power frequency voltages on $U_{d, p e}$ are documented in Table II for different faults. Overvoltages on $U_{d, p p}$ are generally lower since both poles suffer from induced overvoltages of similar phase. It can be noted from Table II that in the analysed test system, the impact of specific faults behaves symmetric towards the center of the lines.

The highest impact on the direct voltage is calculated for a single-phase-to-ground fault, where severity increases towards the middle of the lines. The second critical fault type is a line-to-line-to-ground fault, which behaves opposite and shows highest impact at the far ends of the lines. Three-phase and three-phase-to-ground fault behave similar in a balanced $\mathrm{AC}$ system and show the lowest impact for the examined conditions.

It is obvious that transposition does not show significant impact in the examined transient conditions. For faults on the lines the full transposition is interrupted by the line fault and for faults at the bus, the fault current is mainly supplied by the generator connected to the same bus.

Transient overvoltages are of concern for the insulation level and clearing distance of DC lines and thus must be thoroughly considered when designing a hybrid transmission corridor. 
TABLE II

TRANSIENT POWER FREQUENCY OVERVOLTAGES $U_{d, p e}$ [PU] ON DC LINES

\begin{tabular}{l|ccccccc}
\hline Fault & $L_{1}$ & $L_{2}$ & $L_{3}$ & $L_{4}$ & $L_{5}$ & $L_{6}$ & $L_{7}$ \\
\hline 3-phase fault \\
$T_{0} B_{0} M_{1}$ & 1.05 & 1.06 & 1.04 & 1.06 & 1.04 & 1.05 & 1.05 \\
$T_{0} B_{1} M_{1}$ & 1.01 & 1.02 & 1.09 & 1.07 & 1.09 & 1.02 & 1.02 \\
\hline 3-phase-to-ground fault \\
$T_{0} B_{0} M_{1}$ & 1.06 & 1.05 & 1.05 & 1.06 & 1.05 & 1.06 & 1.06 \\
$T_{0} B_{1} M_{1}$ & 1.02 & 1.02 & 1.05 & 1.08 & 1.10 & 1.02 & 1.02 \\
\hline 1-phase-to-ground fault \\
$T_{0} B_{0} M_{1}$ & 1.21 & 1.21 & 1.28 & 1.37 & 1.25 & 1.24 & 1.24 \\
$T_{0} B_{1} M_{1}$ & 1.21 & 1.21 & 1.27 & 1.36 & 1.24 & 1.21 & 1.22 \\
\hline Line-to-line fault & & & & & & \\
$T_{0} B_{0} M_{1}$ & 1.05 & 1.05 & 1.04 & 1.05 & 1.04 & 1.05 & 1.06 \\
$T_{0} B_{1} M_{1}$ & 1.02 & 1.02 & 1.09 & 1.04 & 1.08 & 1.02 & 1.02 \\
\hline $\begin{array}{l}\text { Line-to-line-to-ground fault } \\
T_{0} B_{0} M_{1}\end{array} 1.28$ & 1.28 & 1.05 & 1.05 & 1.05 & 1.32 & 1.32 \\
$T_{0} B_{1} M_{1}$ & 1.29 & 1.29 & 1.09 & 1.04 & 1.09 & 1.30 & 1.30 \\
\hline
\end{tabular}

Due to the short duration of fast transients the withstand voltages can be higher for switching overvoltages. The induced switching overvoltage due to opening and closing actions of $\mathrm{AC}$ breakers are however higher than induced power frequency voltages. This is both an essential design issue and crucial for system operation, e.g. during $\mathrm{AC}$ line energisation.

\section{DISCUSSION \& CONCLUSION}

A Type 4 MMC simulation model was developed in PSCAD and its suitability for EMT studies was validated. Hybrid transmission corridors connecting monopolar and bipolar 2Terminal VSC converters were modelled and analysed in various configurations.

Test results show that although induced voltages in parallel open circuit DC lines are notable, only a small magnitude of this induced fundamental $\mathrm{AC}$ voltage is calculated in normal operation of the VSC. Analysis of the control signals does not reveal significant fundamental AC content. Since MMC valves are of controllable voltage source type, the submodule capacitors may be considered as batteries with high valve switching frequency. This fast voltage balancing contributes to minimizing the fundamental $\mathrm{AC}$ component on the direct voltage. The current and power oscillations of $0.01 \mathrm{pu}$ are not hazardous to components and showed no concerning unbalance on the AC line side of the analysed system.

It can be concluded that the calculated parameters that quantify the system impact of electromagnetic coupling between AC and DC circuits in a hybrid tower concept do not show significant impact for the analysed conditions during normal operation. The voltage unbalance and total harmonic distortion remain below limits specified in standards. Notable overvoltages however, are recorded when transients in the parallel AC line occur. Pole-to-pole voltage $U_{d p p}$ displays lower overvoltage than pole-to-earth voltage $U_{d p e}$ since both poles are located at comparable distance to the faulted AC line and are subject to induced overvoltages of similar phase. For further comprehensive conclusions, DC side faults, intersystem faults and their impact on both $\mathrm{DC}$ and $\mathrm{AC}$ system require a detailed model of DC protection equipment and controls.

\section{REFERENCES}

[1] H. Nakra, L. Bui, and I. Iyoda, "System Considerations in Converting One Circuit of a Double Circuit AC Line To DC," IEEE Trans. Power Appar. Syst., vol. PAS-103, no. 10, pp. 3096-3103, 1984.

[2] R. Verdolin, A. M. Gole, E. Kuffel, N. Diseko, and B. Bisewski, "Induced overvoltages on an AC-DC hybrid transmission system," IEEE Trans. Power Deliv., vol. 10, no. 3, pp. 1514-1524, 1995.

[3] M. Kizilcay, A. Agdemir, and M. Losing, "Interaction of a HVDC System with $400 \mathrm{kV}$ AC systems on the same tower," in Int. Conf. Power Syst. Transients, Kyoto, 2009, pp. 3-6.

[4] E. Larsen, R. Walling, and C. Bridenbaugh, "Parallel AC/DC transmission lines steady-state induction issues." IEEE Trans. Power Deliv., vol. 4, no. 1, pp. 667-674, 1989.

[5] D. L. Dickmander, S. Y. Lee, G. L. Desilets, and G. L. Granger, "AC/DC harmonic interactions in the presence of GIC for the QuebecNew England phase II HVDC transmission," IEEE Trans. Power Deliv., vol. 9, no. 1, pp. 68-78, 1994.

[6] Y. Jiang and A. Ekström, "General analysis of harmonic transfer through converters," IEEE Trans. Power Electron., vol. 12, no. 2, pp. 287-293, 1997.

[7] J. J. Hu and B. Bisewski, "Evaluation of coupling between dc and ac transmission lines on the same right-of-way : Parametric analysis and mitigation methods," MIPSYCON, 2011.

[8] B. Rusek, K. Vennemann, J. Velasquez, K. Kleinekorte, C. Heising, and V. Staudt, "Special requirements regarding VSC converters for operation of hybrid AC / DC overhead lines," in CIGRE Symp., 2014.

[9] C. Romeis, J. Schindler, J. Jaeger, M. Luther, K. Steckler, and T. Keil, "Induced voltages on HVDC systems by HVAC systems at the same support structure due to capacitive and inductive coupling," in 11th IET Int. Conf. AC DC Power Transm. Birmingham: IET, 2015, pp. 1-7.

[10] U. Straumann and C. M. Franck, "Discussion of Converting a DoubleCircuit AC Overhead Line to an AC/DC Hybrid Line with Regard to Audible Noise," in CIGRE Symp., Bologna, 2011, pp. 1-10.

[11] C. Neumann, B. Rusek, B. Sander, J. Lundquist, and I. Gutman, "Conversion of AC multi-circuit lines to AC-DC hybrid lines with respect to the environmental impact," CIGRE Symp., 2014.

[12] C. C. Davidson and D. R. Trainer, "Innovative Concepts for Hybrid Multi-Level Converters for HVDC Power Transmission," 9th IET Int. Conf. AC DC Power Transm. (ACDC 2010), pp. 1-5, 2010.

[13] A. Lesnicar and R. Marquardt, "An innovative modular multilevel converter topology suitable for a wide power range," 2003 IEEE Bol. PowerTech - Conf. Proc., vol. 3, pp. 272-277, 2003.

[14] CIGRE B4.57, "Guide for the Development of Models for HVDC Converters in a HVDC Grid," 2014.

[15] U. N. Gnanarathna, A. M. Gole, and R. P. Jayasinghe, "Efficient modeling of modular multilevel HVDC converters (MMC) on electromagnetic transient simulation programs," IEEE Trans. Power Deliv., vol. 26, no. 1, pp. 316-324, 2011.

[16] A. Beddard, M. Barnes, and R. Preece, "Comparison of Detailed Modeling Techniques for MMC Employed on VSC-HVDC Schemes," IEEE Trans. Power Deliv., pp. 1-11, 2014.

[17] H. J. Kim, S. Jung, and F. Mosallat, "Validation for Compatible Modular Multilevel Converter Models using PSCAD / EMTDC," pp. 1-6, 2013.

[18] F. Yu, W. Lin, X. Wang, and D. Xie, "Fast Voltage-Balancing Control and Fast Numerical Simulation Model for the Modular Multilevel Converter," IEEE Trans. Power Deliv., vol. 30, no. 1, pp. 220-228, 2015.

[19] H. Saad, C. Dufour, J. Mahseredjian, S. Dennetière, and S. Nguefeu, "Real Time simulation of MMCs using the State- Space Nodal Approach," in IPST, Vancouver, 2013.

[20] H. Saad, S. Dennetiere, J. Mahseredjian, P. Delarue, X. Guillaud, J. Peralta, and S. Nguefeu, "Modular Multilevel Converter Models for Electromagnetic Transients," IEEE Trans. Power Deliv., vol. 29, no. 3, pp. 1481-1489, 2014.

[21] W. Leterme, N. Ahmed, J. Beerten, L. Ängquist, D. V. Hertem, and S. Norrga, "A new HVDC grid test system for HVDC grid dynamics and protection studies in EMT-type software," in IET Conf., 2015, pp. $1-7$.

[22] L. Wu, Impact of EHV/HV Underground Power Cables on Resonant Grid Behavior. Eindhoven: Eindhoven University of Technology, 2014.

[23] B. Gustavsen, G. Irwin, R. Mangelrod, D. Brandt, and K. Kent, "Transmission line models for the simulation of interaction phenomena between parallel AC and DC overhead lines," in Int. Conf. Power Syst. Transients, Budapest, 1999, pp. 61-67. 